\title{
Gestão escolar e IDEB: propostas e suas relações para o crescimento do índice de desenvolvimento da Educação Básica dos Anos Finais do Ensino Fundamental nas Escolas Municipais de Paragominas/PA-Brasil.
}

(School management and IDEB: proposals and their relationships for the growth of the index of development of the Basic Education of the Final Years of Elementary

Education in the Municipal Schools of Paragominas/PA-Brazil.)

Eliane Silva da Costa

Escola Mun. do Ens. Fundamental Maria da Silva Nunes, Paragominas-Pará-Brasil

Páginas 28-41

Fecha recepción: 24-01-2018

Fecha aceptación: 30-03-2018

\section{Resumo.}

Este artigo buscou respostas sobre a Gestão escolar e o IDEB enquanto proposta, qual a relação para o crescimento do índice de desenvolvimento da educação básica dos anos finais do ensino fundamental das escolas municipais de Paragominas/PA de 2013 a 2015. A abordagem do estudo foi qualitativo-quantitativo, do tipo exploratório descritivo, com 0 objetivo de analisar a função do Gestor frente a melhoria da educação e como executa as estratégias para melhorar a qualidade do ensino, bem como, de se empenha para elevar o índice nos exames nacionais tipo do IDEB-MEC. Contudo,, pode-se constatar que das quatro escolas pesquisasdas do Ensino Fundamental, todas obtiveram a diminuição em seu IDEB.

Palavras-Claves: gestão; índice; crescimento; desenvolvimento; educação

\begin{abstract}
.
This article sought answers about school management and the IDEB as a proposal, what is the relation for the growth of the index of development of the basic education of the final years of the elementary school of the municipal schools of Paragominas/PA from 2013 to 2015. The approach of the study was descriptive exploratory type, with the objective of analyzing the Manager's role in the improvement of education and how to implement the strategies to improve the quality of education, as well as to strive to raise the IDEB MEC. However, it can be seen that of the four schools of primary education, all obtained the decrease in their IDEB.
\end{abstract}

Keywords: management; index; growth; development; education 


\section{1.-Introdução.}

Este artigo tem como objetivo explicar, detectar as estratégias e práticas utilizadas pelos gestores e pela equipe escolar nas escolas municipais de Paragominas $A, B, C$ e D nos resultados das avaliações nos exames nacionais em 2013-2015. Assim, 0 interesse em estudar o referido tema surge da necessidade de conhecer como a gestão escolar estabelece as bases para que os processos pedagógicos se desenvolvam com qualidade, devendo conferir autonomia e responsabilidades aos profissionais envolvidos.

Para tanto, este artigo está organizado em tópicos para garantir o entendimento da temática em foco. Buscou-se através da revisão da literatura o aprofundamento do referencial teórico que se articula à investigação, além da análise dos resultados que deve ser ordenado por: análise dos documentos, análise das entrevistas, análise e da observação, entretanto, optou-se por uma abordagem metodológica qualitativa e quantitativa, que será exploratório e descritivo.

A metodologia utilizada envolveu a pesquisa qualitativa para explorar e descrever todas as informações possíveis durante a coleta de dados e do estudo quantitativo, para demonstrar através de números e resultados, bem como analisar tabelas e gráficos relacionados com a diminuição do índice de desenvolvimento da educação básica- IDEB nos anos de 2013 e 2015. Desta forma este estudo adquire mais profundidade em seus procedimentos científicos.

Os exames nacionais do MEC (Ministério da Educação e Cultura) revelam um grande impacto para a cidade e servem de referência nacional para outros municípios pelo seu desenvolvimento no setor primário, secundário, bem como no setor terciário em que se encontra a educação. Temos o IDEB de 2013 e 2015 deste município abaixo do índice nacional, é uma estratégia de relacionamentos entre União, Estados e Município estabelecendo uma relação direta entre governadores e Prefeitos.

Por fim, estes resultados denunciam o fracasso educacional brasileiro e podem evidenciar problemas tanto na gestão escolar como na ação do educador em classe, assim estes dados servem para dar consistência no desenvolvimento do trabalho pedagógico e administrativo das instituições de ensino.

\section{2.-A Gestão e sua relação com o Índice de Desenvolvimento da ed. Básica.}

A trajetória da gestão educacional na administração surge a partir da abordagem clássica de Taylor e Fayol, este "define o ato de administrar como: prever, organizar, comandar, coordenar e controlar." Chiavenato (2004). Colabora com 0 autor ainda Paro (2012: 25) "está se configura como uma atividade exclusivamente humana já que somente o homem é capaz de estabelecer livremente os objetivos a serem compridos". Assim a Administração é uma ciência social e se resume na ação - a função por meio das pessoas para a obtenção dos melhores resultados." 
Desta forma, a administração escolar pautou-se no modelo de administração de empresas, entretanto, como cita Cunha (2012: 34): "é importante ressaltar que a instituição escolar representa a esfera micro dos sistemas de educação, sendo um espaço onde são desenvolvidas as ações eminentemente pedagógicas". Por certo que não é a mesma coisa, porém utilizar-se dos conceitos da administração era a forma mais viável para atender às demandas no âmbito escolar.

Contudo, este aporte na administração levou às ideias da prática de uma gestão educacional baseada numa abordagem democrática para a escola pública e tudo se deu em decorrência dos processos históricos pelos quais passou o Brasil com a redemocratização da sociedade brasileira, idos anos 80 , pois a gestão escolar partindo deste enfoque e por estar pautada em uma gestão administrativa deve comportar-se para desenvolver as competências para alcançar resultados eficientes e eficazes com suporte nos sistemas logísticos e administrativos.

A organização deve ser elementar na rotina da gestão educacional utilizando-se das inúmeras formas de gestar para a melhoria contínua das ações administrativas. A adequação dessa gestão deve estar em acorde com a realidade das instituições de ensino, concorda-se com os autores Limaet al. (2014: 143) quando eles dizem que a gestão educacional se apoiou na administração empresarial e afirmam que mesmo assim as perspectivas dentro das unidades de ensino mudaram quando colocam que:

No entanto, esta foi sufocada por outra concepção de gestão educacional, surgida não dos objetivos de um mundo comercial e competitivo, mas reflexo da natureza, das funções, dos objetivos e dos valores embutidos nas organizações educativas, alicerçados em uma esfera de formação humana e, também, sociocultural, respeitando, portanto, os valores, concepções, especificidades e singularidades que diferenciam este ambiente da mera administração capitalista.

A concordância da gestão educacional com a administrativa deve, mesmo seguindo 0 molde dos conceitos da área da administração, coadunar-se com as ações pedagógicas e educacionais das instituições de ensino. Portanto a área administrativa deve possibilitar à gestão educacional suporte para o desenvolvimento de rotinas administrativas que vão também favorecer resultados com eficiência no que se refere à administração de projetos e outros recursos financeiros.

Atualmente, a realidade das instituições de ensino no Brasil perpassa por outras óticas que vão além de ações nas áreas pedagógicas e educacional, em sua essência. A atuação da escola também depende dos inúmeros projetos em parceria com os governos, daí a importância de levar a característica administrativa para dentro da escola a fim de esta se adéque às exigências desses projetos que trazem recursos financeiros e que precisam que os gestores tenham o mínimo de conhecimento para prestação de contas. 
Portanto como Cezario (2013: 1) se reporta: O conceito de gestão está associado a moderna conjuntura política de Gestão Participativa, onde surgem mecanismos de participação popular, como uma iniciativa inovadora chamada de Orçamento Participativo, que com sua aplicação possibilita a participação da sociedade na definição das prioridades, compartilhando o poder de decisão e planejamento antes restrito aos representantes eleitos pelos mesmos.

$\mathrm{Na}$ análise dos autores Lima et al. (2014: 134) a gestão na escola para ser boa precisa atender às seguintes prerrogativas para obter resultados favoráveis: Para uma boa gestão da escola torna-se evidente a responsabilidade dos gestores no planejamento, na organização, na direção e no controle das atividades instituídas pela mesma. Nessa perspectiva, a "nova escola" assume um compromisso claro de executar seu trabalho com eficiência, eficácia e qualidade em busca de resultados positivos junto às comunidades assistidas aplicando os modelos de gestão, princípios e funções administrativas.

\section{1.-Teorias Administrativas.}

Em decorrência das crescentes transformações sociais e econômicas do mundo a partir, principalmente do século XIX, a administração precisou sofrer nova abordagem inserindo novas variáveis (tarefas, estrutura, pessoas, ambiente, tecnologia e competitividade) que em conjunto influenciaram as teorias administrativas. Na análise de Chiavenato (2008: 24): Apesar de todas as críticas aos postulados clássicos e aos enfoques tradicionais da organização, os princípios de Administração, a departamentalização, a racionalização do trabalho, a estrutura linear ou funcional, enfim, a abordagem clássica nunca foi totalmente substituída por outra abordagem. Todas as teorias administrativas posteriores se assentaram na Teoria Clássica, seja como ponto de partida, seja como, critica para tentar uma posição diferente.

Ainda para Chiavenato (2008: 53): "As organizações são projetadas e administradas de acordo com certas teorias administrativas. Cada teoria administrativa baseia-se em convicções sobre a maneira pela qual as pessoas se comportam dentro das organizações". Inicialmente os autores clássicos buscavam desenvolver estudos que tinham como objetivo a criação de uma ciência administrativa que tivesse como enfoque a solução dos problemas organizacionais, baseado na divisão do trabalho, especialização, coordenação e atividades de linha de staff, em lugar das leis científicas. Neste contexto histórico, que surgiram as Teorias da Administração dividindo-se em: Teoria Científica e Teoria Clássica e tem início a abordagem clássica da administração.

\section{2.-Teoria Científica.}

A abordagem clássica da Administração ergue-se a partir do século XX com dois pioneiros, engenheiros, sendo um americano e outro europeu - Frederick Taylor e Henry Fayol, respectivamente. Ambos desenvolveram princípios gerais com bases 
científicas, mesmo com pontos de vistas diferentes, elaboraram postulados que se complementam e ao mesmo tempo vieram para organizar a Administração como ciência.

A Administração Científica desenvolvida por Taylor entre outros engenheiros dentro dos Estados Unidos tinha como ideia básica que para aumentar a produtividade da empresa teria que aumentar a eficiência a nível operacional, ou seja, no nível dos operários. Chiavenato (2008: 3-4) destaca: "Esse cuidado analítico e detalhista permitia a especialização do operário e o reagrupamento de movimentos, operações, tarefas, cargos, etc" a ênfase nas tarefas feita no nível do operário para Chiavenato (2008: 3) predominava: “... na divisão do trabalho do operário, uma vez que as tarefas do cargo e o ocupante constituem a unidade fundamental da organização."

O principal objetivo deste tipo de Administração era propiciar o máximo de prosperidade para empregadores e empregados. Sendo que esta identidade de interesses se preocupou mais com as técnicas do que com a própria filosofia da Administração Científica, pois para Chiavenato (2010: 206): "A abordagem humanística substituiu a ênfase antes colocada nas tarefas (Administração Cientifica) e na estrutura organizacional (Teoria Clássica e da Burocracia) pela ênfase colocada nas pessoas e nos grupos sociais." Assim foi o primeiro passo para a busca de uma teoria administrativa com outra visão, diante deste cenário surge a Teoria Clássica da Administração.

\section{3.-Teoria Clássica.}

A Teoria Clássica da Administração surge no início do século XX em meio às mudanças progressivas, principalmente quanto à industrialização; em virtude deste panorama houve a necessidade de padronização e simplificação da produção além da especialização da mão de obra a fim de alcançar a eficiência nos resultados. Esta teoria se desenvolveu na Europa, o renomado autor Chiavenato (2008: 3) cita: Um era americano, Frederick Winslow Taylor, e iniciou a chamada Escola da Administração Cientifica preocupada em aumentar a eficiência da indústria por meio da racionalização do trabalho do operário. O outro era europeu, Henri Fayol, e desenvolveu a chamada Teoria Clássica, preocupada em aumentar a eficiência da empresa por meio de sua organização e da aplicação de princípios gerais da Administração em bases científicas.

Ainda conforme Chiavenato (2006: 56) a administração Clássica diz que: A organização é um meio para atingir a eficiência máxima sob o aspecto técnico e econômico. Daí a visão anatômica da organização, em termos de uma organização formal, apenas isto é, a síntese dos diferentes órgãos que compõe a estrutura organizacional, suas relações e suas funções dentro do todo e que asseguram a máxima eficiência. Assim, esta teoria clássica possui como seu principal objeto de estudo a ênfase na estrutura.

Contudo, no âmbito da Administração pontua Chiavenato (2006), sobre a Administração Científica que na realização de suas tarefas desenvolve-se um 
trabalho mecânico, repetitivo e individualizado, enquanto a Teoria Clássica define as funções básicas da empresa como: Prever, organizar, comandar, coordenar e controlar e estes podem ser aplicados a qualquer tipo de organização ou empresa.

$\mathrm{Na}$ contraposição à Teoria Científica a Clássica Fayol enfatiza a estrutura para que a organização seja eficiente, traz a abordagem anatômica e estrutural e faz o caminho inverso nessa estrutura que parte do todo organizacional para as partes podendo a divisão do trabalho ser tanto horizontal quanto vertical em níveis de autoridade e departamentalização, respectivamente.

\section{4.-Teoria das Relações Humanas.}

Esta surge em oposição a Teoria Clássica da Administração. Sua origem está na necessidade de humanizar e democratizar a administração no desenvolvimento das chamadas ciências sociais (Sociologia, psicologia etc.). Na prática essa teoria surge com a experiência de Hawthorne (A Western Electric equipamentos e componentes telefônicos. Na época, desenvolvia uma política de pessoal que valorizava o bemestar dos operários, mantendo salários satisfatórios e boas condições de trabalho.) Para Chiavenato (2000: 103). A "Teoria Clássica pautava-se na ideia atomística do homem enquanto que na Teoria das Relações Humanas 0 indivíduo não está isolado, mas ao contrário se reúne em grupos sociais". Estas causas são necessidades ou motivos, pois são forças conscientes ou inconscientes que levam as pessoas a um determinado comportamento. A motivação refere-se ao comportamento que é causado por necessidades intrínsecas sendo dirigidas aos objetivos que podem satisfazer essas necessidades. Chiavenato (2006) define que os três níveis de motivação são: necessidades fisiológicas, psicológicas e de auto realização.

A explanação acima não exaure 0 assunto, todavia é de fundamental importância entender tais teorias, pois cada uma delas possibilita ao gestor escolar a utilização dos princípios da Teoria da Administração para organizar a escola de forma eficiente e eficaz, buscando resultados favoráveis para a melhoria do processo de ensino e aprendizagem. O gestor escolar adotando tais estratégias pode favorecer progressivamente a efetividade de metas educacionais, entre elas, nos exames nacionais que medem dados de ensino tipo-IDEB (Índice de Desenvolvimento da Educação Básica).

Nesse panorama o que se percebe é que as mudanças ocorreram dentro da administração educacional e as diversas abordagens surgiram para fomentar 0 conteúdo do qual se apropria a gestão para desenvolver-se na escola. Portanto na visão de Lima et al. (2011: 132): A abordagem sociológica é cronologicamente a mais atual e a que tem apresentado maior contribuição ao estudo da política e da administração educacional brasileira. Seu quadro de referência foi idealizado no contexto da realidade nacional, considerando elementos oriundos das análises de cunho sociológico, antropológico, econômico, político, filosófico, psicológico e estatístico, sem, todavia, perder de vista a dimensão pedagógica. 


\section{3.-Metodologia.}

Dessa forma, consideramos importante apresentarmos os passos desenvolvidos na elaboração desse artigo, pois utilizou em seu desenho de investigação o modelo nãoexperimental. Para Sampieri (2006) a pesquisa não-experimental se realiza sem a manipulação das variáveis, ou seja, o investigador observa os fenômenos tal qual ocorre no contexto natural para depois analisá-lo.

O enfoque desse estudo é de natureza descritiva, de abordagem quantitativa e qualitativa. Para Sampieri (2010):" em um estudo descritivo seleciona-se uma série de questões e mede-se ou coleta-se informações sobre cada uma delas, para assim descrever o que se precisa". Nesse sentido, a descrição das estratégias e práticas utilizadas pelos gestores educativos nas escolas da cidade de Paragominas, para 0 aumento do índice de desenvolvimento da educação básica (IDEB).

Destacam-se também o universo da população pesquisada. As quatro instituições de Paragominas A, B, C e D um IDEB abaixo do índice nacional em 2015 comparado ao ano de 2013, assim foi realizada a escolha das Instituições de Ensino, onde se optou pela técnica da observação, entrevista e guia de levantamento documental

A partir dessas colocações aponta-se os sujeitos da pesquisa: foram 4 Gestores em atividade, 4 coordenadores nos centros educativos e 4 educadores nos centros educativos das escolas municipais do ensino fundamental de Paragominas ( $A, B, C$ e D), no período estabelecido para a coleta de dados.

Antes de adentrar as entrevistas foi preparado um formulário de perguntas para a aplicação nas escolas em foco, ficha de observação, guia de levantamento documental, guia de entrevista, para que facilitasse a análise da pesquisa. Vale enfatizar, que estes são os instrumentos e foram construídos com base nas quatro áreas da investigação da pesquisa (IDEB, Baixo índice do IDEB do IDEB, Estratégias e práticas de gestão), com 0 propósito de obter respostas para a fundamentação desse estudo.

Já em relação às técnicas, desenvolveu a análise dos conteúdos explanados pelo entrevistado, juntamente com as observações do caderno, acoplados ao levantamento documental, entre eles são: alguns documentos Institucionais (histórico, lotação, enturmação dos educadores e levantamento de alunos matriculados e evadidos), projetos pedagógicos desenvolvidos nas escolas em estudo, atividades desenvolvidas em sala pelos educadores.

\section{4.-Discussão dos resultados.}

\section{1.-Áreas da Gestão Escolar.}

A gestão escolar passou por diversas mudanças em sua evolução, pois até bem pouco tempo empregava-se 0 termo administração escolar, todavia esta designação tornou-se inadequada dada à nova dimensão pela qual a escola se transformou além 
de seu caráter eminentemente pedagógico. Com a democratização do Brasil ocorreram mudanças na gestão das unidades de ensino fazendo com que a escola tivesse mais autonomia, logo as decisões nas áreas administrativa, financeira e pedagógica passaram a ser mais decisivas para o rumo da escola.

Na perspectiva de Libâneo, Oliveira e Toschi (2012: 411): "No caso da escola, a organização e a gestão referem-se ao conjunto de normas, diretrizes, estrutura organizacionais, ações e procedimentos que assegurar a racionalização do uso de recursos humanos, materiais, financeiros e intelectuais assim como a coordenação e acompanhamento do trabalho das pessoas.". Neste contexto os autores resumem a atuação do gestor dentro da escola perpassando por todas as áreas tanto administrativa, financeira e a principal que é a pedagógica.

"A partir do momento em que todos os envolvidos passam a conhecer a realidade e objetivos da escola, começam a se sentir parte integrante ajudando a melhorar a realidade". (Veiga, 2011: 13), assim o autor destaca a importância do trabalho democrático e coletivo na construção do PPP. Ainda nesse panorama Santos e Santos (2014: 6) complementam: Se percebe que algumas escolas vêm sendo gerenciadas como uma empresa, propondo formar sujeitos que prontamente atenda a sociedade globalizada e formandos que siga a risca um ensino e a aprendizagem que atenda 0 mercado de trabalho, para tanto, o coordenador pedagógico deve contrariar para contribuir com a escola procurando atuar como sujeito reflexivo e que promova participação, tendo em vista que o mesmo contribua com 0 ensino e a aprendizagem de qualidade.

Nesse contexto, a gestão escolar em sua atuação profissional na educação destinada a realizar o planejamento, a organização, a liderança, a orientação, a mediação, a coordenação, tem sua divisão baseado no objetivo de atender às novas demandas da comunidade escolar. E para cumprir este objetivo é importante ter que construir o PPP, "é necessário convencer aos professores, funcionários e equipe escolar a trabalhar mais, proporcionando situações que lhes permitam aprender a pensar e a realizar o fazer pedagógico de forma coerente". (Veiga, 2011: 15).

Afirma ainda Gonçalves (2012: 108): "A educação escolar possui a função de promover a apropriação de saberes, procedimentos, atitudes e valores por parte dos alunos, pela ação mediadora do ensino, e pela gestão e organização da escola". Portanto, se corrobora com as afirmações acima citadas, quanto à importância de uma gestão escolar eficiente e voltada para democratização das decisões, organização e planejamento administrativo pedagógico.

O que se observa neste propósito da gestão escolar é que através destes tipos de gestão possa contribuir para a gestão educacional. O gestor escolar poderá influenciar-se das proposições estabelecidas para balizar suas ações administrativas e assim deliberar com todos que fazem parte do ensino-aprendizagem com o objetivo de atingir metas e objetivos com o fim precípuo de melhorar o horizonte pedagógico da escola. Libâneo, Oliveira e Toschi (2012: 420) afirmam: "A organização e a gestão 
são meios para atingir as finalidades do ensino. É preciso ter clareza de que 0 eixo da instituição escolar é a qualidade dos processos de ensino-aprendizagem que, mediante procedimentos pedagógico-didáticos, propiciam melhores resultados de aprendizagem." Portanto, se faz necessário discorrer de maneira sucinta sobre 0 assunto para melhor entender os conceitos que permeiam tais conceitos.

\section{3.-Estratégia da gestão escolar.}

Evidencia-se que nos espaços escolares, o desenvolvimento de estratégias através dos projetos como a Olimpíada Brasileira de Língua Portuguesa, Olimpíada de Matemática (OBMEP) e a Olimpíada Brasileira de Astronomia (OBA), os conteúdos a serem desenvolvidos devem ser baseados em uma metodologia instigante gerando satisfação no ensino e no aproveitamento escolar do aluno. Na perspectiva de gestão, o gestor é "julgado" pela maneira que realiza o seu trabalho e pelos resultados que obtêm no espaço escolar, pois precisa garantir a aprendizagem efetiva de seus alunos e ainda administrar cada canto e recanto da escola, uma vez que deve ter um caráter educativo, contribuindo, assim, para tornar o espaço físico cada vez mais humano e humanizador, mais atrativo, mais lúdico, mais vivo e mais pedagógico.

\section{4.-Práticas utilizadas pelos gestores.}

Gonçalves (2012: 104): define para 0 gestor na área administrativa: Com tudo é importante liderar e administrar, em perfeito equilíbrio com a cultura organizacional do sistema educacional. Essa proposta defendida diretamente a compreensão de como 0 Gestor educacional encaminha e lidera a própria ação tanto administrativa como pedagógica de seu trabalho.

Na dimensão pedagógica envolve a organização do trabalho escolar no que diz respeito à elaboração do projeto pedagógico, no planejamento anual, nas reuniões pedagógicas, nos conselhos de classe, na recuperação da aprendizagem dos alunos com menor rendimento escolar, na organização do tempo e do espaço escolar, no acolhimento às famílias e aos alunos, no índice de aprovação e correção da defasagem idade/aprendizagem.

Para Vasconcelos (2010), no conjunto das funções do coordenador pedagógico a principal e Desenvolver a mediação que os professores devem fazer em sala de aula: Acolher, provocar, subsidiar e interagir, bem como, ajudar na elaboração e concretização da proposta pedagógica da escola.

Nesse fim, a diversidade das questões que cercam o papel do gestor escolar, pois esse deve mobilizar, buscar parcerias, delegar responsabilidades, promover a integração e articulação entre as pessoas, assim a gestão de recursos humanos deve oferecer sustentação para esta ação, pois somente com estes parâmetros 0 espaço escolar cresce, visando um padrão de qualidade para mudanças de direção e caminhos, melhorando assim, suas metas nos exames Nacionais tipo IDEB.

O Índice de desenvolvimento da educação básica- IDEB e seu crescimento no Brasil 
Considerando que o IDEB foi operacionalizado em 2007, é calculado com base na taxa de rendimento escolar (aprovação e evasão) e no desempenho dos alunos no SAEB (Sistema Nacional de Avaliação da Educação Básica) e na Prova Brasil, esse indicador nacional também serve de informativo à população em geral.

Para que pais e responsáveis acompanhem o desempenho da escola de seus filhos, basta verificar o IDEB da instituição, que é apresentado numa escala de zero a dez. Da mesma forma, gestores acompanham o trabalho das secretarias municipais e estaduais pela melhoria da educação. 0 índice é medido a cada dois anos e 0 objetivo é que o país, a partir do alcance das metas municipais e estaduais, tenha nota 6 em 2022 - correspondente à qualidade do ensino em países desenvolvidos (Ministério da educação, s./d.).

Nos anos em que a Prova Brasil e o Saeb são aplicados, as secretarias de educação que possuem turmas de quarta e oitava séries (quinto e nono anos) do ensino fundamental recebem os cadernos Matrizes de Referência, Temas, Tópicos e Descritores e estes materiais trazem informações aos gestores e professores sobre os pressupostos teóricos que embasam a avaliação, os descritores e uma série de exemplos de itens (questões) sobre língua portuguesa e matemática das séries a serem avaliadas.

Segundo o MEC: As Matrizes de Referência SAEB é o referencial curricular do que é avaliado, em cada disciplina e série, informando assim, as competências e habilidades esperadas dos alunos, pois na área de língua portuguesa, 0 aluno terá que ser capaz de produzir e compreender textos dos mais diversos gêneros e, em diferentes situações comunicativas, tanto na modalidade escrita e oral, na matemática o foco é a resolução de problemas (MEC, 2008:17).

Diante desse cenário, o Brasil precisa intensificar a melhoria na qualidade educacional com profissionais da educação comprometidos e com uma visão holística à realização de seus fins, dessa maneira podemos mudar a realidade educacional de nosso país, e isso é bem visível no gráfico abaixo.

Figura 1-Resultado geral do IDEB BRASIL nos anos finais: 2007 e 2009

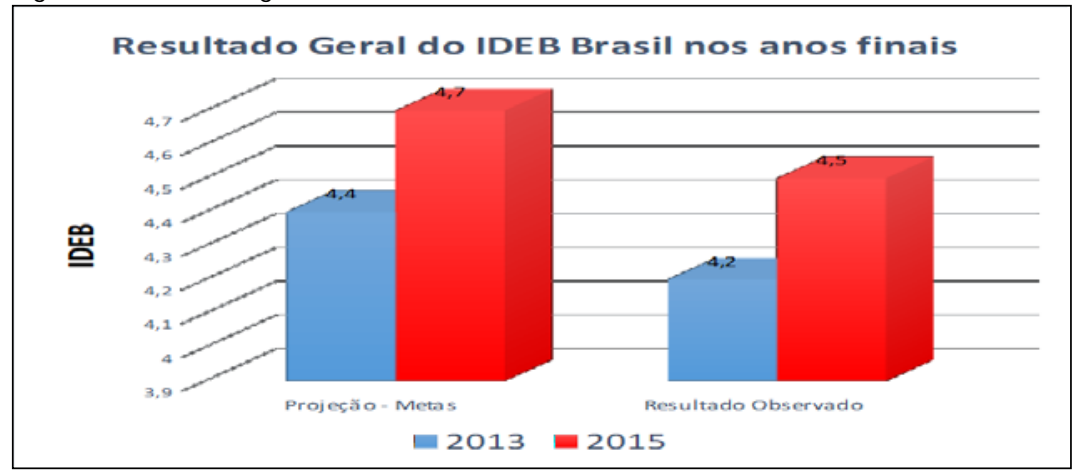

Fonte: SAEB e Censo Escolar. 
Partindo desse pressuposto, é preciso um esforço maior dos estados que estão com o IDEB abaixo da meta. Eles devem ter como objetivo não só a elevação, mas a qualidade dessa aprendizagem.

Figura 2- Resultado geral do IDEB Pará nos anos finais: 2013 e 2015.

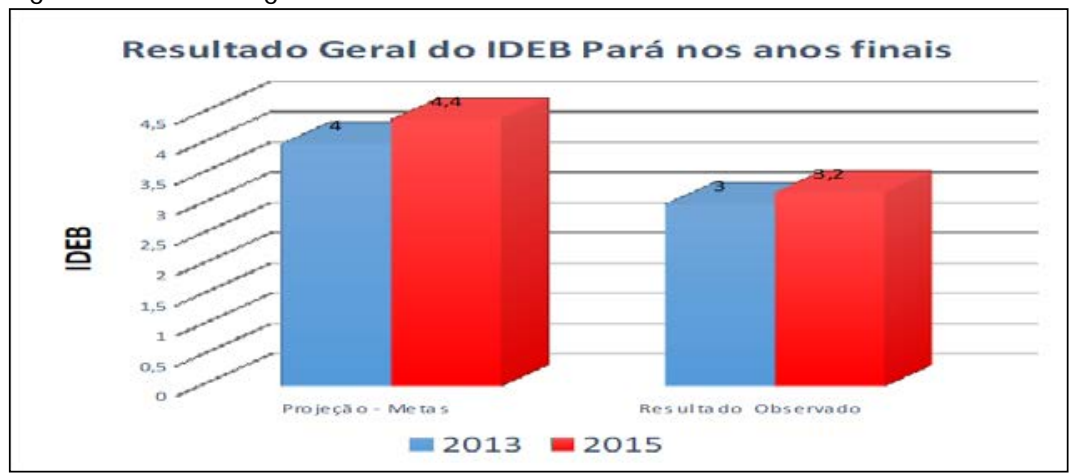

Fonte: SAEB e Censo Escolar.

Com base na planilha de dados do INEP observa-se que o Estado do Pará nas séries finais o ensino fundamental em 2015, teve um considerável aumento em relação à 2013, mesmo não conseguindo atingir o seu indicador tipo-IDEB, tal análise é importante, pois permite notar que no estado do Pará, vários municípios precisam melhorar suas metas projetadas, entre eles está o foco desta pesquisa, Paragominas.

Figura 3- Resultado geral do IDEB Paragominas nos anos finais: 2013 e 2015.

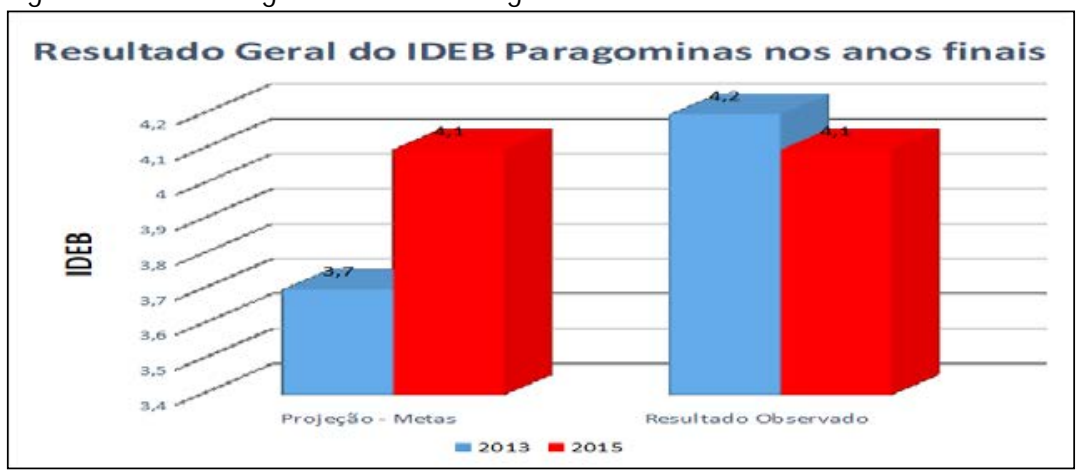

Fonte: SAEB e Censo Escolar.

Entende-se que com esses resultados, o Brasil, seus estados e municípios precisam oferecer um saber sistematizado e não fragmentado, devendo priorizar ao aluno condições para que este seja crítico, e capaz de enfrentar os desafios de um mundo capitalista e competitivo. 
Contudo, a não inserção de estratégias e práticas mais efetivas no ambiente escolar contribuiu como um dos fatores determinantes para o não crescimento do índice de desenvolvimento da educação básica no município de Paragominas/PA/BR

\section{5.-Conclusão.}

A presente pesquisa, através da análise dos dados obtidos permitiu identificar 0 alcance do objetivo geral e da problemática da pesquisa: A não inserção de estratégias e práticas mais efetivas no ambiente escolar contribuiu como um dos fatores determinantes para o não crescimento do índice de desenvolvimento da educação básica no município de Paragominas/PA/BR? As questões foram respondidas e confirmadas pela própria fala dos sujeitos, os gestores educacionais das respectivas escolas em estudo A, B, C e D que utilizaram de seus conhecimentos pedagógicos em suas instituições de ensino, mais a falta de ações mais concretas, gerou, assim, a diminuição dos seus índices nos Exames Nacionais tipo- IDEB.

As características comuns das unidades de ensino pesquisadas foram à forma de como a equipe pedagógica utilizou as suas estratégias e práticas para a valorização e acolhimento aos seus estudantes, através de projetos e programas desenvolvidos em suas escolas, motivando assim os mesmos, mais os resultados ainda eram ineficazes, em todas as áreas do saber, principalmente nas provas de Língua Portuguesa e Matemática.

Nota-se então que todas as escolas realizaram o percurso de ações que permeiam 0 Plano de Desenvolvimento da Educação - PDE, assim como a política de valorização do servidor, pois esse enfoque propõe aos especialistas da educação, políticas como meio de crescimento pessoal e profissional, exigências essas que devem ser desenvolvidas dentro do mercado de trabalho almejado por todo profissional.

Constata-se que, as ações desenvolvidas pelos gestores escolares nos referidos estudos foram pautadas e fundamentadas na LDB no 9394/96, nos Parâmetros Curriculares Nacionais (PCNs), pelos cadernos entregues às escolas do SAEB e prova Brasil.

Portanto, apesar de todas as estratégias e práticas utilizadas por todos os educadores 0 crescimento não foi efetivo, mais é preciso ter a expectativa que as culturas organizativas das escolas delinearão caminhos ainda mais úteis e consistentes para uma melhor evolução do conhecimento, mas para isso, é preciso ainda um maior comprometimento de toda a sociedade e de todos os gestores, somente dessa forma será eficaz a qualidade do ensino em nosso País.

\section{0.-Bibliografia.}

Chiavenato, I. (2000). Introdução à Teoria Geral da Administração: uma visão abrangente da moderna administração das organizações. Rio de Janeiro: Elsevier. 
Chiavenato, I. (2006). Princípios de Administração: o essencial em teoria geral da administração. Rio de Janeiro: Elsevier.

Chiavenato, I. (2008). Administração geral e publica. Provas e Concursos. $2^{\mathrm{a}}$.ed. Rio de Janeiro: Elsevier,

Chiavenato, I. (2010). Prefácio. In Gestão de pessoas, o novo papel dos recursos humanos nas organizações. 3.ed. Rio de Janeiro: Elsevier.

Cruz, P., Monteiro L. (2013). Anuário brasileiro da educação básica. Brasil. Moderna, C.E.O. (2012). A gestão escolar e sua relação com os resultados do IDEB, um estudo em duas escolas municipais. Salvador: Dissertação. 172 f. il.

Cezario, G.A. (2013). A democratização da administração pública: a experiência do orçamento democrático estadual e a gestão participativa. $93 \mathrm{f}$. Trabalho de Conclusão de Curso (Graduação em Administração) Centro de Ciências Exatas e Sociais Aplicadas ação (Mestrado). Bahia: Faculdade de Educação, Universidade Federal.

Gonçalves, C.V. (2012). Liderança educacional: um desafio para administração escolar na escola municipal de ensino fundamental Prof. Valdomiro Mendes Rodrigues. In Revista internacional de adición y lenguaje, Logopédia, apoyo a la integración y Multiculturalidad. Junio, Volumen 1, n4, p.97-110.

Lei de Diretrizes e base da Educação Nacional. (1996). nº 9.394/96. Brasília: Ministério da Educação e cultura.

Libâneo, J.C., Oliveira, J.F., Toschi, M.S. (2012). A construção da escola pública avanços e impasses. In. Educação escolar políticas, estrutura e organização. São Paulo: Cortez.

Lima, M.A.M., Tahim, A.P.V.O. Arnaud, J.C., Souza, A.M.C., Pontes, J.A.A. (2014). Funções da gestão educacional: Planejamento, organização, direção e controle nas escolas municipais de Aquiraz/CE, Brasil. In Revista Eletrônica de Educação, v.8, n.3, p.127-146. Recuperado de: http://www.reveduc.ufscar.br/index.php/reveduc/articlepdf.

Prova Brasil. (2007). avaliação do rendimento escolar, ensino fundamental, matrizes de referências, tópicos e descritores. Brasília: Ministério da Educação e cultura. Brasília: Instituto Nacional de Estudos e Pesquisas Educacionais Anísio Teixeira.

Plano de Desenvolvimento da Educação. (2008). PDE, prova do ensino fundamental: matrizes de referência, tópicos e descritores. Brasília: MEC. 
Sampieri, R.H.U et. al. (2006). Metodologia de La investigacion. 4a ed. Mc.Graw-Hill. México: DF.

Santos, L.A., Santos, F.LS. (2014). Uma reflexão sobre o trabalho do coordenador pedagógico, o Significado da Identidade Profissional. Alagoas: VII encontro de pesquisa em educação.

Vasconcellos, C.S. (2009). Coordenação do trabalho pedagógico do projeto político pedagógico ao cotidiano da as la de aula. São Paulo: Libertad.

Vasconcellos, C.S. (2010). Sobre o Papel da Supervisão Educacional Coordenação Pedagógica. In: Coordenação do Trabalho Pedagógico do projeto político pedagógico ao cotidiano da sala de aula. 11ª . ed. São Paulo: Libertad. 